\title{
Risk Management in the Agri-food Sector
}

\author{
Hrabrin Bachev ${ }^{1}$
}

ABSTRACT

This paper incorporates the interdisciplinary New Institutional Economics in a comprehensive framework for analyzing risk management in the agri-food sector. First, it specifies the diverse types of agri-food risks (natural, technical, behavioral, economic, policy, etc.) and the modes of their management (market, private, public, and hybrid). Second, it defines the efficiency of risk management and identifies the factors (personal, institutional, dimensional, technological, and natural) of governance choice. Next, it presents stages in the analysis of risk management and the improvement of public intervention in the governance of risk. Finally, it identifies the contemporary opportunities and challenges for risk governance in the agri-food chain.

KEY WORDS: $\quad$ risk management; market, private, and public governance; agri-food chain

JEL Classification: D23, D81, L14, L22, L25, O17, Q12, Q13, Q18, Q52

${ }^{1}$ Institute of Agricultural Economics, Bulgaria

\section{Introduction}

The management of diverse risks (natural, market, criminal, policy, etc.) in the agrarian and food sectors are issues with particular topical interest (Babcock, 2004; CIPS, 2012; Deep \& Dani, 2009; EU, 2011; Notarnicolaa et al., 2012; OECD, 2008; Olsson \& Skjöldebrand, 2008; Ramaswami et al., 2008; RPDRM, 2012; Schaffnit-Chatterjee, 2010; Shepherd et al., 2006; Trench et al., 2011; Tummala \& Schoenherr, 2011; Weaver \& Kim, 2000). Evolving uncertainty, risks and crises associated with the progression of natural environments, products, and technologies, social demands, policies, and globalization present new challenges to the current systems of risk management.

Risk management studies in the agri-food sector predominately focus on technical methods and capabilities to perceive, prevent, mitigate, and recover from diverse threats and risks (Barker, 2005; Beni et

Correspondence concerning this article should be addressed to: Hrabrin Bachev, Institute of Agricultural Economics, 125 Tzarigradsko shosse, blok 1, Sofia 1113, Bulgaria, e-mail: hbachev@yahoo.com al., 2012; DTRA \& IIBR, 2011; Hefnawy, 2011; Jaffee et al., 2008; Luning et al., 2006; Zhang \& Li, 2012). Most economic publications apply a Neoclassical approach, study risks as commodities regulated by market supply and demand, and model farmers' "willingness to pay" for insurance contracts relative to agents' risk aversion, risk probabilities, and the magnitude of damages (Gerasymenko \& Zhemoyda, 2009; OECD, 2011). Market and private failures are acknowledged, and needs for public intervention in agrarian insurance are increasingly recognized (Brewer, 2010; EU, 2011; OECD, 2008).

Risk management analysis largely ignores significant risks based on "human nature" (bounded rationality, opportunism), critical factors for managerial decision making such as institutional environment and transaction costs, and diverse alternative modes of management (market, private, collective, public). As a result, the efficiency and complementarities of risk management modes cannot be assessed properly. Despite advances in risk management technologies and "menus" of risk reduction, mitigation and coping strategies, numerous failures/challenges (production, safety, environmental, 
etc.) persist in the agri-food sector (Dani and Deep, 2010; EU, 2011; Humphrey and Memedovic, 2006; Luning et al., 2006; OECD, 2011; Sarkar et al., 2012). Consequently, attention is directed to the system of governance that eventually determines the exploration of technological opportunities and the state of agri-food security (Bacha et al., 2009; Bachev, 2010).

This paper incorporates interdisciplinary New Institutional Economics (Coase, 1960; Furuboth and Richter, 1998; North, 1990; Williamson, 1981; 1996) in a comprehensive framework for analyzing risk management in the agri-food sector. First, it specifies the types of agri-food risks and the modes of their management. Second, it defines the efficiency of risk management and identifies factors of governance choice. Next, it presents the stages in risk management analysis and improvements of public intervention. Finally, it identifies contemporary opportunities and challenges for risk governance in the agri-food chain.

\section{Agri-food risks and modes of governance}

Risk is any current or future hazard (event) with a significant negative impact(s). It is either idiosyncratic (accidental, low probability, unpredictable events) or systematic (high probability, "predictable" events). The risk/threat could be of natural (adverse weather, insectrelated, catastrophes), technological ("pure" technical failures), or human (individual or collective actions/ inactions), or a combination of these types. Individual behavior and actions that cause risks include agent's ignorance (lack of knowledge, information, training) and/or errors; risk-taking strategy (accepting above "normal" risk); mismanagement (inadequate planning, prevention, recovery); opportunistic behavior (precontractual cheating, post-contractual "moral hazard"); criminal acts (damaging/stealing or invading an individual's property); terrorist attacks (environmental contamination or other actions that aim to produce "mass terror"), etc. Collective actions are sources of risks that relate to: economic dynamics and uncertainty (changing demands, price volatility, competition, market "failures" and imbalances such as "lack" of labor, credit, inputs); collective orders (professional standards, strikes, trade and community rules and restrictions); or public orders (political instability and uncertainty, evolution in informal and formal norms, public "fail- ures" such as bad, delayed, or under/over intervention, law and contract enforcements, mismanagement, "inefficiency by design"), etc.

The agri-food sector can face risks associated with each component (dairy farms, food processors, traders) or it could cause risks (risk from farming, from food processing, from food-distribution). Risk can be internal to agri-food chains such as hazards caused by one element affecting another within the sector. Risk can be external and associated with external factors (natural environment, government policy, international trade) and/or effecting external components (consumers, residents, industries, nature). Risk can be private, when it is assumed by individuals, collectives, entities, or industries, or it can be public when it affects large groups, communities, consumers, or future generations.

The magnitude of risk is large when an event has both a great likelihood of occurrence and substantial negative consequences - such as damage to humans and livestock (health and property), inferior yields and income, loss of market position, food and environmental contamination, etc. When risk is considerable, it would likely be associated with significant costs that often can hardly be expressed in monetary terms - human health hazards, degraded soil, and loss of biodiversity and eco-system services. Thus, "rational" agents that maximize their own welfare will be interested in investing in risk prevention and reduction.

In a narrow (technical) sense, risk management comprises individual, collective and public action(s) for reducing/eliminating risk and its consequences. In a broader sense, risk management is the specific system of social order (governance) that is responsible for the particular behavior(s) of agents and determining way(s) to assign, protect, exchange, coordinate, stimulate, and dispute risks, rights, resources, and activities (Bachev and Nanseki, 2008). In a particular (socio-economic, technological, natural) environment, the specific system of risk governance that is "put in place" is intimately responsible for the efficiency of the detection, prevention, mitigation, and reduction of threats/risks and their consequences.

Generic forms and mechanisms of risk governance are (Figure 1) as follows:

Private modes ("private and collective order") include diverse private initiatives and special contractual 


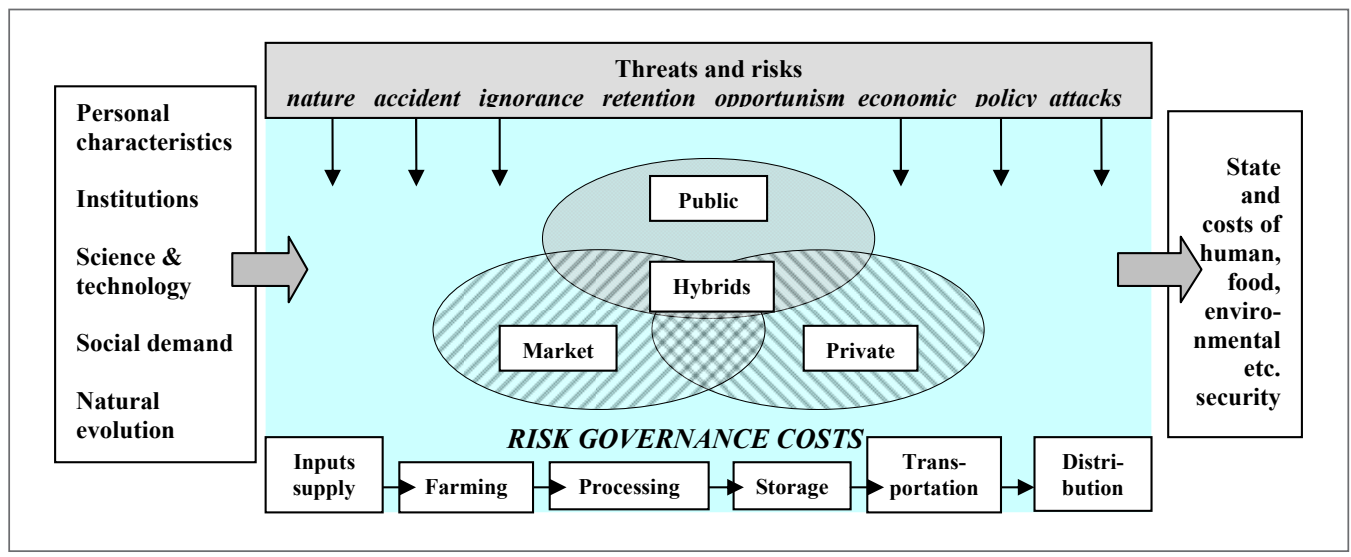

Figure 1. Generic risks, factors, stages, and modes of risk governance in the agri-food sector

and organizational arrangements tailored to the features of risks and agents, such as codes of behavior, diverse (relational, security, future) contracts, cooperatives, associations, business ventures, etc. Market modes ("invisible hand of market") include various decentralized initiatives governed by free market price movements and competition, such as risk trading (selling/buying insurance), future contracts and options, production/ trade of special (organic, fair-trade, origins) products, etc. Public modes ("public order") include various forms of third-party public (government, international) intervention in market and private sectors, such as public information, regulations, bans, assistance, funding, assurance, taxation, provision, etc.

Sometimes, risk management can be conducted effectively though "self-management" such as production management, adaptation to industry and formal standards, "self-insurance" though stock investments, financial reserves, etc. Primitive forms of on-farm risk management through production management improvement are widespread: control and security enhancement, use of appropriate crop varieties (resistance to pests, diseases, and weather), structure of technology and production, product diversification, dislocation, etc. Similarly, offfarm enterprise/income diversification is a major risk management strategy for most European farms (Bachev and Tanic, 2011). Very often, risk management requires an effective governance of relations with other agents such as the exchange and regulations of rights, the alignment of conflicts, the coalition of resources, and collective or public actions on regional, national, and transnational scales. Thus, a risk could be "managed" through market modes (purchase of insurance, hedging with future price contingency contracts), private modes (contractual or literal integration, cooperation), public forms (state regulation, guarantee, compensation), or hybrid combinations of other forms.

\section{Risk management efficiency}

Risk governance modes have different efficiencies because they have dissimilar potentials to reduce the likelihood and impact of risks and involve different costs (Bachev, 2010). Market or collective governance has advantages over internal mode/"own protection" because market governance allows for the exploration of economies of scale/scope in preventing risks and managing negative consequences. However, risk trading or sharing is associated frequently with significant transaction costs for finding the best partners and prices, formulating/disputing terms of exchange, forming coalitions, and safeguarding against new risks from the opportunistic behavior of counterparts/partners. Consequently, markets and private sectors "fail" to effectively manage the existing/likely risks, and there is a need for "state intervention" in risk management (cooperation and assistance for farmers, public cost-sharing or provisions, mandatory assurance regulation). Thus, "governance matters" and applying proper risk management structure are important parts of the process of optimization (effective allocation) of resources.

Following Coase's logic (1960), if property rights were well-defined and transaction costs were zero, 
then all risks would be managed in the most socially efficient way, independent of the specific mode of governance (although some types of risks would not exist or be significant, e.g., risks related to adverse human behavior). Then, agents would either sell their risk to specialized market agents or safeguard against risk through private contract terms or join risk-sharing organizations of interested parties. Risktaking would be distributed (exchanged, shared) by agents according to their will, while total costs for risk prevention, assurance, reduction, and recovery would be minimized. The rational choice for an individual agent would be to eliminate significant risk altogether by selling risk to specialized market risk-takers. Market governance would optimize risk-taking, minimize "technological costs" for risk assurance and explore the recovery potential for economies of size/scope at national/transnational scales.

When property rights are not well-defined or enforced and transaction costs (associated with distribution, protection, and exchange of rights of individuals, groups, and generations) are high, then the type of governance is essential to cover the extent and costs of risk protection. For example, the internal (ownership) mode is often preferred over outside (market, contract) modes because of the comparative protective and costs advantages for "standard" natural/behavioral risk management. Frequently, enormous transaction costs can block the development of insurance markets or the emergence of mutually beneficial risk-sharing organizations. For instance, despite "common" interests and huge risk minimization potentials, collective risk-sharing organizations are rarely developed by smallholders.

Formal and informal institutional restrictions might make some modes of risk governance impossible. For example, risk-assuring monopolies/cartel arrangements are illegal in many countries, while most entrepreneurial risk-taking is endorsed (according to the "low risk-low profit" principle). Thus, not all modes of risk governance are always feasible in every socioeconomic setting. However, if the costs of illegitimate forms are low, the possibility for disclosure is low and enforcement and punishment are insignificant, while benefits are considerable, then more effective "gray" or black governance prevails.

Individuals differ significantly in their capacity to recognize, adopt, and pay for prevention, and manage risk. For example, risk-taking farmers prefer risky but more productive forms (e.g., bank credit for new, profitable ventures). In addition, agents have quite different interests in effective management of particular risk(s) because they receive dissimilar benefits and costs from risk management.

There is no single universal form of management for diverse types of risks. According to the specific features of each risk (origin, probability, likely damages), there will be different most effective governance forms. For example, while low probability "standard" (natural, criminal) risk might be effectively governed with classical market contracts (purchase of insurance), most behavioral risks require special private modes (branding, long-term or interlink contracts, vertical integration), and high damage risk from terrorist attracts necessitates specialized public forms (intelligence, security enforcement). Hence, depending on the type and severity of risk, the interests and personal characteristics of individuals, and the specific natural, economic and institutional environments, there will be different (most) efficient forms of governing a particular type of risk. Consequently, some governance mix will always exist to manage the diverse risks associated with the agri-food sector.

Sometimes, effective risk management leads to the reduction or removal of a particular risk. Often, complete risk elimination is either costly ("unaffordable" by individuals/society) or practically impossible (when uncertainty and transaction costs are enormous). For example, certain natural risks will always exist despite the system of management. Moreover, it is practically impossible to write "compete" contracts (for trading risk) that include all probable future contingencies and subsequent rights and obligations for each party (Vierø, 2012; Williamson, 1996), and some transaction risk will always remain. Therefore, effective risk management is always connected with the needs for some trade-off between benefits from reducing particular risks (saved costs, minimized impacts) and related costs for risk governance. Thus, some "uncovered" risk will normally remain.

Individual modes can offer effective protection from different/multiple risks. Moreover, management of one type of risk might be associated with exposure to a new type of risk/cost, e.g., vertical integration eliminates "market risk" but creates risk 



\section{Factors of governance choice}

The forms of risk management depend on the risk type, personal characteristics, institutional environment, progress in science and technology, culture, social education and preferences, evolution of the natural environment, etc. (Figure 1). Risk features such as the origin, probability of occurrence, likely damages, and scale are important factors for the choice of governance. For instance, local risk could be managed through private modes, while most market and environmental risks require collective actions at the regional, national or transnational level. For high probability and harmful risks, agents prefer more secure/expensive modes such as security investments, purchase of insurance, maintaining reserves, taking hostages, and interlinked organizations. However, many smallholders cannot afford the related costs and practice no or primitive forms of risk management, such as cash-and-carry deals and product diversification. In that case, there is the need for third party (government, international assistance) intervention, though insurance, support, safety nets, etc., to decrease the vulnerability of farmers.

Personal and behavioral characteristics of agents include interests, preferences, knowledge, capability, risk-aversion, reputation, trust, "contractual" power, and opportunism. For instance, some risks are not perceived (unknown) by private and public agents; therefore, no risk management is put in place. In some cultures, the cooperative is the preferred mode of organization; an experienced/trained farmer might design and manage a larger organization/hired labor and more outside (credit, insurance, inputs supply) contracts that are adapted to his needs. Additionally, a risk-taking entrepreneur prefers riskier, but more productive ventures.

Behavioral factors such as the bounded rationality and opportunisms of individuals are identified as being responsible for transaction costs and, thus, for organizational choice (Williamson, 1996). They are widely studied in insurance theory as sources of cheating on both sides of contracts (Derrig, 2002).

Agents do not possess complete information about the economic system (risks, price ranges/dynamics, trade opportunities, policy development) because the collection and processing of such information (multiple markets, future events, intention for cheating) is very expensive or impossible. To optimize decision- making, they allocate resources to "increasing imperfect rationality" (data collection, analyses, forecasts, training, consulting) and select forms (internal organization, "selling out" risk) that minimize the related risks/costs.

Agents are also prone to opportunism, and they frequently take advantage of opportunities to extract extra benefits/rent. If there was no opportunism, only risk that is related to bounded rationality (natural, technical) would remain and the consequences would be recovered easily with the cooperation and mutual benefits (risk sharing) of the parties. Pre-contractual opportunism ("adverse selection") occurs when some of the partners use "information asymmetry" to negotiate advantageous contract terms. Post-contractual opportunism ("moral hazard") occurs when a counterpart takes advantage of the impossibility of complete observation of activities (by another partner, third-party) or takes "legal advantage" of unforeseen changes in the exchange conditions (costs, prices, regulations). Third form of opportunism ("free ride") occurs in large organizations where individual benefits are not proportional to individual efforts/costs and everyone expects other people to invest in the organizational development and benefit from the new organization (Olson, 1969). Bounded rationality often makes it costly/impossible to distinguish opportunistic from non-opportunistic behavior (e.g., a farmer finds that purchased seeds were of poor quality during the harvest), and agents protect their rights, investments, and transactions from the hazards of opportunism through means such as ex-ante efforts to find reliable counterparts and design efficient modes for partner commitments and ex-post investments for overcoming (monitoring, controlling, stimulating cooperating) possible opportunism during contract execution (Williamson, 1996).

In the agri-food sector, opportunism is widespread before signing insurance contracts (not disclosing information for possible risks) or during contract execution (not taking actions for reducing damages when events occur or consciously provoking damages in order to get insurance premiums). These events increase the insurance prices and limit the utilization of insurance contracts by small enterprises. The insuree also "discovers" the insurer's opportunism after the occurrence of a harmful event and finding that the assurance terms (protected risks, extent of coverage, dam- 

(mutual expectations) rather than the specification of obligations is practiced. Partners (self)restrict themselves from opportunism and are motivated to settle emerging difficulties and continue their relations (as in the situation of frequent reciprocal trades). When unilateral dependency exists (unwanted "exchange", quasi or full monopoly), then the dependent side must protect their investments against possible opportunism (behavioral uncertainty/certainty) through integrating transactions (unified organization, joint ownership, cooperative) or by safeguarding them with interlinked contracts, exchanges of economic hostages, development of collective organizations for price negotiations, lobbying for government regulations, etc.

Activities/transactions are particularly difficult when the appropriability of rights for behavior, products, services, and resources is low. The costs for protection, detection, verification, and third-party/court punishment of unwanted exchanges are extremely high (bounded rationality). Agents either over-produce (negative externalities) or under-organize activities (positive externalities) unless they are governed by efficient private or hybrid modes such as cooperation, strategic alliances, long-term contracts, trade secrets, or public orders.

Progress in science and technology significantly improves risk management and facilitates the diversification of forms, e.g., the introduction of new (resistant) plant and livestock varieties; the mechanization and standardization of operations and products; and the application of information, forecasting, monitoring, storage, and transportation technologies that significantly improve risk management in the agri-food chain (COST, 2009; Hefnawy, 2011; Notarnicolaa et al., 2012). However, modern applications of science and technology are also associated with production/exposure to new types of risk, such as greenhouse gas emissions, genetic contamination, natural resource depletion, and over-dependence on technology.

Evolution of the natural environment - global warming, extreme weather, plant and animal diseases, drought, flooding and other natural disasters are posing new challenges for risk management in the agrifood sector (Hefnawy, 2011; OECD, 2011).

The identification of "critical factors" of risk management decisions, the range of feasible forms, and the efficiency (costs, benefits) of governance modes for individual agents, stages, subsectors, countries, food chains and public are subjects for special microeconomic study.

Comparative analysis is to be employed to compare the feasible forms and select the most efficient alternative that reduces the overall risk to an "acceptable" level and minimizes the total (risk assurance and governance) costs. Most elements of risk governance efficiency are difficult to quantify, such as individuals' characteristics, amounts of risk, levels of benefits and the costs associated with each mode. The "measurement problems" associated with the transaction benefits and costs are well-specified (Bachev, 2011b) and prevent the utilization of traditional (Neoclassical) models simply by adding a new "transaction" or risk management activity (Furuboth and Richter, 1998).

Extended Qualitative (Discrete structural) analysis can be used as operationalized by Williamson (1981). For assessing the efficiency of risk governing structures, the features of risk to be managed (probability, significance, acceptance level, collective action needs) and its critical (institutional, technological, behavioral, etc.) factors are to be matched with comparative advantages (potential) of alternative modes to inform, stimulate appropriate behavior, align interests, and overcome, reduce, control, share, dispute, and minimize overall costs of risk.

In a specific market, the institutional, technological and natural environment effective risk governance choice depends on a combination of risk features (probability of occurrence, likely magnitude of damages) and critical dimensions of activities/transactions (appropriability, assets specificity, and frequency), (Figure 2). High "standard" risks might be effectively managed through free market modes such as standard/classical insurance, inputs supply, marketing, etc. contracts. Highly probable and damaging risks with a good appropriability and frequency of transactions between the same partners require a special (e.g. relational) contract. The later form is also appropriate for the risks surrounding with low uncertainty, high assets specificity and appropriability, and occasional character of the relations between the counterparts.

Principally, risks combined with high specificity, appropriability and frequency might be effectively managed though a vertical integration (internal risk management, contract forward or backward integration for 


\begin{tabular}{|c|c|c|c|c|c|c|c|c|}
\hline \multirow{2}{*}{\multicolumn{4}{|c|}{$\begin{array}{r}\text { Critical dimensions } \\
\text { of activity }\end{array}$}} & \multicolumn{5}{|c|}{ Appropriability } \\
\hline & & & & \multicolumn{4}{|c|}{ High } & Low \\
\hline \multirow{4}{*}{\multicolumn{4}{|c|}{ Risk features }} & \multicolumn{4}{|c|}{ Assets Specificity } & \\
\hline & & & & \multicolumn{2}{|c|}{ Low } & \multicolumn{2}{|c|}{ High } & \\
\hline & & & & \multicolumn{4}{|c|}{ Frequency } & \\
\hline & & & & Low & High & Low & High & \\
\hline \multirow{4}{*}{ 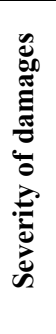 } & \multirow[b]{2}{*}{ 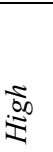 } & \multirow{4}{*}{ 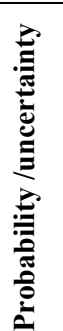 } & בे & $\mathrm{M} / \mathrm{CC}$ & $\mathrm{M} / \mathrm{CC}$ & SC & VI & \multirow{2}{*}{ PO } \\
\hline & & & 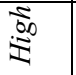 & $\mathrm{M} / \mathrm{CC}$ & SC & $\mathrm{CO}$ & $\mathrm{CO}$ & \\
\hline & & & ఏ్ & na & na & SC & VI & na \\
\hline & 亏े & & $\stackrel{500}{50}$ & $\mathrm{M} / \mathrm{CC}$ & $\mathrm{M} / \mathrm{CC}$ & TPI & VI & CO\& TPI \\
\hline
\end{tabular}

M - free market; CC - classical (standard) contract; SC - special contract; VI - vertical (internal) integration; CO - collective organization, TPI - needs for a third-party involvement; PO - needs for a public organization

Figure 2. Principle modes for risk governance in the agri-food sector

risk sharing or mitigation). Highly likely and menacing risks combined with a high assets specificity and a good appropriability call for a collective organization (cooperation, collective action). Moreover, such risk/ costs sharing organization could be easily initiated and maintained since the condition of a high risk and assets dependency is in place.

However, serious transaction risk exists when assets specificity is combined with high uncertainty, low frequency, and good appropriability. In that case, the elaboration of a special structure for private transactions is unjustified, specific (risk-reducing) investments are not made, and the activity/restriction of activity fails to occur on an effective scale ("market and contract failure"). Third-party (private, NGO, public) involvement is necessary (assistance, arbitration, regulation) to make the transactions more efficient or possible. The unprecedented development of special origins, organic farming, and "fair-trade" systems are good examples; there are increasing demands (premium) for organic, original and fair-trade products associated with some forms of (natural, poverty, labor, quality) risk management, but their supply could not be met unless effective trilateral governance, including independent certification and control, is put in place. Similarly, for risks with a low appropriability a third party (public) intervention is necessary to secure the effective risk management. Moreover, while a high probability low danger risks need a collective organization assisted by a third-party ("quasi" public organization for risk sharing and mitigation), the high damaging risks necessitate a public organization.

\section{Stages in analysis and improvement of risk management}

The analysis and improvement of risk governance in the agri-food chain is to include following steps: First, the existing and emerging threats and risks are identified. The persistence of certain risks is a good indicator for ineffective management. Modern science offers quite reliable and sophisticated methods for assessing various risks to or caused by agri-food chain (DTRA \& IIBR, 2011; Trench et al., 2011; Ueland et al.; 2012).

Second, the existing and other feasible modes of risks governance are specified, and their efficiency and prospects of development are assessed. The efficiency of individual modes shows their capability for risk detection, prevention, mitigation, and recovery at low costs, while sustainability reveals their "internal" potential to adapt to socio-economic, technological, 
and environmental changes and associated threats and risks. A holistic framework for assessing the efficiency and evolution of governing modes is suggested by OECD (2011) and Bachev (2010). That stage identifies the deficiencies of dominating (market, private, public) modes to solve existing and emerging risks, and determines the needs for (new) public intervention. For instance, when appropriability associated with transaction/activity is low, there is no pure market or private mode to protect against the associated risks. Respecting others" rights or "granting" risk protection rights to others could be governed by "good will" and charity actions (e.g., the eco-sustainability movement initially evolved as a voluntary activity). However, voluntary initiatives can hardly satisfy entire social demands, especially if they require significant costs. The emergence of special large-member organizations for dealing with low appropriability to cover entire "social" risks is a very slow and expensive process, and it is unlikely to be sustainable in the long run (free riding). There is a strong need for third-party public intervention to make protection from risk possible or more effective, such as purely public organizations (public assurance for natural and economic disasters) or "quasi-public" modes (collective organizations assisted/ordered by third parties) for high probability, low damage risks (Figure 2).

Third, the alternative modes for public intervention to correct failures (market, private, public) are identified, their comparative efficiency is assessed, and the best one(s) is selected. The comparative assessment is to be made on (technically, economically, politically) feasible forms as mode(s) that minimize the total risk management (implementing and transaction) costs selected. The analysis is to take into account the overall private and social costs, including the direct and indirect (individual, third-party, tax payer, assistance agency) expenses, and private and public transaction costs. The latter costs often comprise a significant portion of the overall risk management costs and are usually ignored; these costs include the costs for coordination, stimulation, and mismanagement of bureaucracy; individuals' participation and use of public modes (expenses for information, paper work, fees, bribes); community control and reorganization of bureaucracy (modernization/liquidation of public modes), (opportunity) costs of public inaction, etc.
Initially, the existing/emerging problems (difficulties, costs, risks, failures) in the organization of market and private governance are specified. Appropriate pubic involvement is used to create an institutional environment for making private investments less dependent, decreasing the uncertainty surrounding market and private transactions, intensifying exchanges, and protecting private rights and investments such as when the State establishes and enforces quality, safety, and eco-standards, certifies producers, regulates employment relations, transfers management rights on natural resources, etc., thus increasing the efficiency of market and private risk management.

Next, the feasible modes for increasing appropriability are considered. Low appropriability is often caused by unspecified or badly specified private rights and obligations. Sometimes, the most effective government intervention is to introduce and enforce new private and group (property) rights on diverse types of risks and trading; natural resources; food safety; a clean environment; tradable quotas for products, inputs, and emissions; intellectual property; and origins. That intervention transfers the organization of transactions into market and private governance, liberalizes market competition, and induces private incentives (investments) in certain risk management.

In other instances, it is more efficient to establish public regulations for risk minimization for the utilization of resources, products, and services (standards for labor, product, environmental safety); the introduction of foreign species, GMC, and (water, soil, air, comfort) contamination; bans on inputs, products, and technologies; regulations for trading ecosystem service protection; trade regimes; mandatory risk and eco-training, and licensing of operators, etc.

In other instances, using incentives and restrictions of the tax system is the most effective method. Different types of tax preferences are used widely to create favorable conditions for the development of (sub) sectors and regions, forms of organization, population segments, activity types. For example, environmental taxation on emissions or products (inputs, outputs) can be applied to reduce use or emissions of harmful substances; tax reduction can be used to overcome negative consequences of natural disasters, etc.

In some cases, public support of private organizations is the best mode for intervention. Programs for 

sector, food-chain, national, and international, according to the types of risks and scales of collective actions necessary to mitigate risks. It is not a one-time exercise to complete the last stage with a perfect system of risk management. Rather, it is a permanent process to improve risk management along with the evolution of the socio-economic and natural environment, individual and community awareness, modernization of technologies, etc. Moreover, public (local, national, international) failure often prevails, which also brings us into the next cycle in the improvement of risk management.

For the application of this suggested approach, in addition to the traditional (statistical, industry, etc.) information, new types of data are necessary for diverse risks and forms of governance, critical factors for each agent, and levels of benefits and costs. Such data are collected through interviews with agri-food chain managers, stakeholders, and experts in these areas.

\section{Contemporary opportunities and challenges for risk governance in the agri-food chain}

Modern agri-food chains involve millions of actors with different interests, multiple stages, and diverse risks requiring complex, multilateral, and multilevel governance on a large scale. For instance, there are several million farmers, several hundred thousand different food processors and retailers, and 500 million consumers in the EU. The figures are much larger if the total number of global agents who are involved in the EU agri-food chain are taken into account.

The variety of existing and emerging threats and risks (natural, technological, behavioral, etc.) in the modern agri-food chains are identified (DTRA \& IIBR, 2011; Humphrey and Memedovic, 2006; OECD, 2011). Diverse market and private modes evolved to address specific risks driven by ethics, competition, consumer demand, business initiatives, trade opportunities such as direct marketing, voluntary and industry standards, insurance schemes, guarantees, fair-trade, trade with brands, origins, and organic and quality products. Different bilateral and multilateral private forms are used widely to safeguard against risks, explore benefits, and facilitate exchange such as clientalisation, contractual arrangements, cooperation, and complete backward/ forward integration. Special trilateral forms emerged to enhance security and the confidence of partners and consumers, including independent (third-party) certification and inspection. Trade internationalization is increasingly associated with collective private actions (standards, control mechanisms) on transnational and global scales (e.g., GLOBALGAP). Property (security/safety) rights modernization and market and private "failures" brought about the needs and modes for $p u b$ lic interventions (assistance, regulations, provision) as the scope and stringency of publically imposed rules expand constantly to embrace new products, methods, dimensions (human, animal, plant, eco-health), hazards (GMC, nanotechnology, terrorism), and information requirements. Furthermore, the globalization of exchange and threats/risks increasingly require setting transnational public order (ISO, WHO, FAO, WTO). For example, there are common (traceability, precaution, communication) principles (food, veterinary, phytosanitary, feed, environmental etc.), legislation, and implementing and enforcing agencies (EFSA, ECDC, ECHA) for the agri-food chains and imports in the EU.

Consumers' concerns about food safety risks have increased significantly after major food safety "events"/crises in recent years (avian flu; mad cow and foot-and-mouth diseases; poultry salmonella; contamination of dairies, berries, and olive oil; natural and industrial disasters, etc.). For example, since 2005 the number of respondents "worrying about food-safety problems" in the EU increased, and as many as $48 \%$ of European consumers (in Bulgaria, approximately $75 \%$ ) indicated that consumed food was "very or fairly likely" to damage their health (Eurostat, 2010).

There are a number of (new) opportunities for risk governance in the agri-food chain (Figure 3): First, advances and dissemination of technical food chain, training and risk management methods (microbiological, genetic, electrical, laser, robotic, immunological, chemical and biosensor, nanotechnology, ICT etc.), integral and food chain approaches, and research, monitoring, testing, decision making, and forecasting capabilities for risk-detection, assessment, prevention, and mitigation (COST, 2009; Trench at al., 2011). For instance, advances in detection, assessment, and mitigation methods and technologies associated with biological and chemical risks are presented by DTRA \& IIBR (2011). 


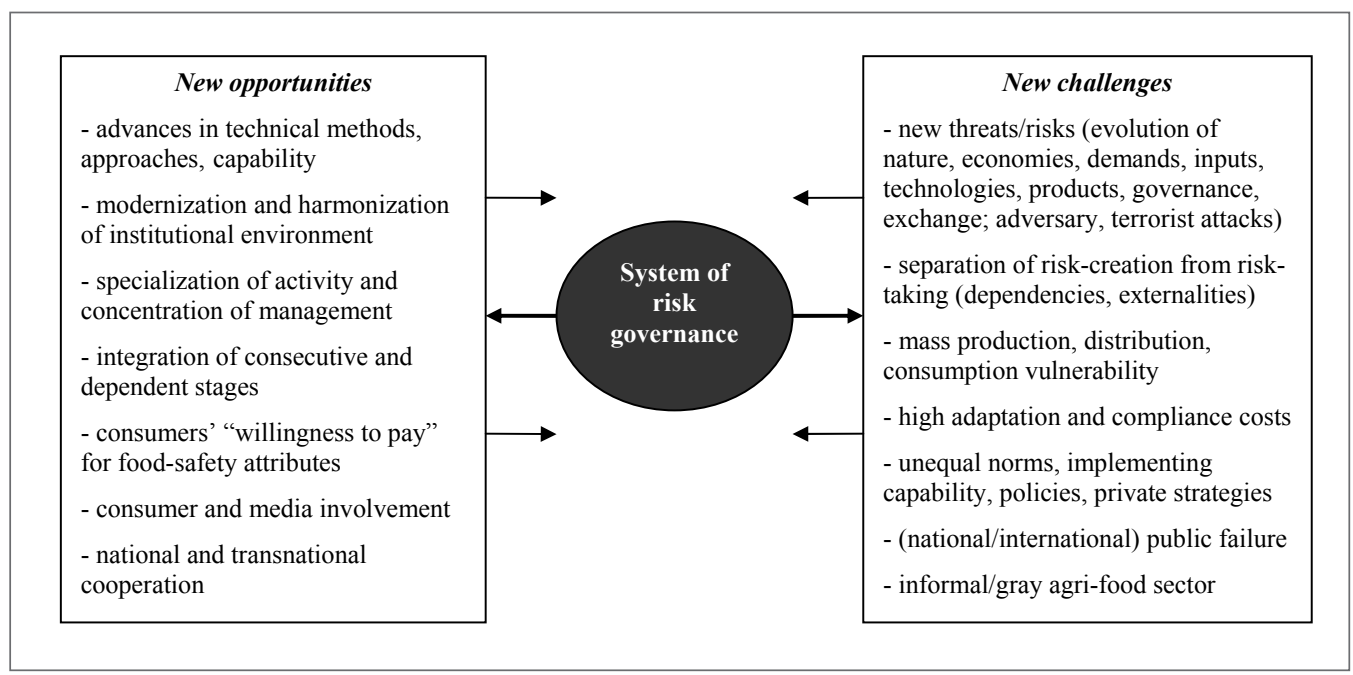

Figure 3. Opportunities and challenges for risks governance in the agri-food chain

Second, modernization and international harmonization of institutional environments (private, corporate, collective, NGOs, public food-safety and related standards, rules, enforcements). For instance, EU membership improves considerably the "rules of the game" in new member states; market access rules and/ or "corporate responsibilities" induce transformations in the agri-food sector of exporting countries in Africa, Latin America, and Asia.

Third, considerable development of specialization of activities (including risk taking, monitoring, management) and concentration of (integral) management in food-production, processing, servicing, and distribution allowing centralized innovation and enforcement; time, scale, and scope economies; and easy third-party control. For instance, the market share of the three largest food retailers comprise between 27 and $91 \%$ in the EU states (Eurostat, 2010), and food safety training, certification, inspection, and information are large international businesses (Humphrey and Memedovic, 2006).

Fourth, quasi or complete integration of the consecutive or dependent stages in food chains are creating mutual interests and effective, long-term means for risk perception, communication, and management. For example, in Bulgaria the (raw) milk supply is closely integrated by (dairy) processors through onfarm (collecting, testing) investments and interlinks (inputs, credit, and service supply against milk delivery) contracts with smallholders, while dairy marketing is managed by branding (standards, bio labels) and long-term contracts (Bachev, 2011a).

Fifth, the increasing consumer "willingness to pay" for food safety attributes such as chemical and hormone bans, safety and inspection labels, and original and special products (Trench at al., 2011). The latter justify and make economically possible the pay back of costs for special governance.

Sixth, the growing involvement of consumers (representation, organizations) and media and the national and transnational (information, technical, managerial, training, certification) cooperation of partners and stakeholders are improving the options available to agents, inducing public and private actions, and enhancing risk management communication, efficiency, and speed.

Modern developments are also associated with a number of (new) challenges for risk governance in the agri-food chain: i) Emergence of new threats, risks, and uncertainty associated with the evolution of the natural environment (climate change, water stress, "new" plant, animal and human hazards) as well as new human-induced economic, financial, food security and safety, water, environmental etc. crises, on large (transnational, global) scales. 
ii) Increasing new threats, risks, and uncertainty connected with inputs, technologies, and product differentiation and innovation. For example, the Fukushima nuclear accident severely affected the agri-food sector in Japan and beyond, and there are uncertainties associated with the growing application of nanotechnologies and GMCs, etc. (Eurostat, 2010).

iii) Increasing specialization and concentration of activity and organizations which separate "risk creation" (incidents, ignorance, opportunisms) and risk taking (unilateral dependencies, quasi-monopolies, spill-overs, externalities). Thus, risk assessment, pricing, communication, disputing, and liability through (pure) market and private modes are very difficult and costly. For instance, cheating, misleading, and pirating are common in food chain relations, including high information asymmetry, detection, disputing, and punishment costs. It is indicative that for food risk information, consumers in the EU place greater trust in "health professionals", "family and friends", "consumers associations", and "scientists" rather than "food producers" and "supermarkets and shops" (Eurostat, 2010).

iv) Widespread mass production, distribution, and consumption increase the vulnerability of the agrifood chain expanding scope and severity of natural, incidental, opportunistic, criminal, and terrorist risks. For instance, in Europe there is a growing number of official notifications based on market and non-member country controls, food poisoning, consumer complaints, company self-checks, border screenings, and rejections (Eurostat, 2010).

v) Increasing adaptation and compliance costs (capital, training, certification, documentation, etc.) for rapidly evolving markets and institutional environments that delay or prevent the reformation of small farms and food chain enterprises (Trench et al., 2011; Bachev, 2010). For instance, in Bulgaria, the adaptation of dairy and meat processors to EU standards continued for 10 years, and two-thirds of them ceased to exist before the accession of their country (Bachev, 2011a).

vi) Public and private food quality and safety standards, and the efficiency of their enforcement, differ considerably between industries, countries, and regions (Humphrey and Memedovic, 2006). That is result of unequal norms (GAPs, formal and informal rules) and implementing and enforcing capability, or deliberate policies, or private strategies (e.g., multinationals that sell the "same" products with different quality in different countries). "Double/multiple standards" are responsible for exchange inequality and dissimilar threats and risks exposure of individual agri-food systems.

vii) Wide spread "public failures" in food chain (risk) management such as bad, inefficient, delayed, or under/over interventions; gaps, overlaps, infighting, and contradictions among different agencies and rules; high bureaucratic costs; and unsustainable costs and underfunding. For instance, the Bulgarian Food Agency was established after a 5-year delay; the Acquis Communautaire are still not completely implemented (capability deficiency, mismanagement, corruption); and trust of the EU rather than national institutions prevails (Bachev, 2010). There are also numerous instances of international assistance or governance failures when institutions are "imported" rather than adapted or designed for specific local conditions (Bachev, 2010).

viii) Production, marketing, and consumption traditions, high food or governance costs, and deficiencies of will and capacity are responsible for the persistence of the high risk informal/gray agri-food sector around the globe without effective control and substandard, fake, and illegitimate products and activities. For instance, only one-third of Bulgarian dairy farms comply with EU milk standards, only $0.1 \%$ possesses safe manure pile sites, and half of the milk production is consumed by the producer at home, exchanged or directly sold (Bachev, 2010).

ix) Multiplying new threats and risks associated with adversary (competitor) and terrorist attacks, and emerging governing and exchange forms (street sales; internet, phone and mail order sales; shopping trips). These risks all require specific/non-traditional risk management methods and modes such as guards, policing, intelligence, multi-organizational and transnational cooperation, etc.

\section{Conclusion}

We have demonstrated that governance, along with technical, information and other issues, play a central role in risk management analysis and design. The entire spectrum of diverse types of threats and risks (natural, market, health, criminal, policy etc.), specific (natural, 

Dani/Papers/1060574/Investigating_risk_management_capability_within_UK_food_supply_chains

Deep, A., \& Dani, S. (2009). Managing Global Food Supply Chain Risks: A Scenario Planning Perspective, Paper presented at POMS 20th Annual Conference, May 1-4, 2009, Orlando.

DTRA \& IIBR (2011). Exploring Multidiciplinary Approaches to Chemical and Biological Defense (2011), Proceedings, DTRA \& IIBR Workshop, June 19-23, 2011, Eilat.

Derrig, R. (2002). Insurance Fraud. The Journal of Risk and Insurance, 69(3), 271-287.

Furuboth, E., Richter, R. (1998). Institutions and Economic Theory: The Contribution of the New Institutional Economics. Ann Arbor, MI: The University of Michigan Press.

Gerasymenko, N., \& Zhemoyda, O. (2009). New Challenhes for Risk Management in Agri-food Industry. Paper presented at EAAE 113th Seminar, September 3-6, 2009, Chania.

EU (2011). From the farm to the fork, European Union, Brussels. Retrieved from: http://epp.eurostat. ec.europa.eu/cache/ITY_OFFPUB/KS-32-11743/EN/KS-32-11-743-EN.PDF

Eurostat (2010). Consumers survey. Retrieved from: http://ec.europa.eu/public_opinion/archives/ebs/ ebs_354_fact_bg_bg.pdf

Frank, J., \& Garcia, P. (2011). Measuring the cost of liquidity in agricultural futures markets: Conventional and Bayesian approaches. Agricultural Economics, 42(1), 131-140.

Hefnawy, M. (Ed.). (2011). Advances in Food Protection Focus on Food Safety and Defense, Dordrecht, The Netherlands: Springer.

Humphrey J., \& Memedovic, O. (2006). Global Value Chains in Agri-food Sector (Working Paper). The United Nations Industrial Development Organization.

Jaffee S., Siegel, P., \& Andrews, C. (2008). Rapid Agricultural Supply Chain Risk Assessment. Retrieved from: http://siteresources.worldbank.org/INTCOMRISMAN/Resources/RapidAgriculturalSupplyChainRiskAssessmentConceptualFramework.pdf

Luning P., Devlieghere, F., \& Verhé, R. (Eds.). (2006). Safety in the agri-food chain. Wageningen Academic Publishers: Wageningen, The Netherlands.
North, D. (1990). Institutions, Institutional Change and Economic Performance. Cambridge, UK: Cambridge University Press.

Notarnicolaa, B., Hayashib, K., Curranc, M., Huisinghd, D. (2012). Progress in working towards a more sustainable agri-food industry. Journal of Cleaner Production, 28(June 2012), 1-8.

OECD (2008). Managing Risk in Agriculture: a Holistic Approach. Paris. Retrieved from http:// www.oecd.org/tad/agriculturalpoliciesandsupport/45558582.pdf

OECD (2011). Managing Risk in Agriculture Policy Assessment and Design. Paris. Retrieved from http:// www.oecd-ilibrary.org/agriculture-and-food/ managing-risk-in-agriculture/foreword_97892641161461-en;jsessionid=9q394go5q8fsf.x-oecd-live-02

Olson M. (1969). The Logic of Collective Actions: Public Goods and the Theory of Groups. Cambridge, MA: Harvard University Press.

Olsson, A., \& Skjöldebrand, C. (2008). Risk Management and Quality Assurance Through the Food Supply Chain - Case Studies in the Swedish Food Industry. The Open Food Science Journal, 2, 49-56.

Ramaswami, R., Ravi, S., \& Chopra, S. (2008). Risk management in agriculture, (Discussion papers No. 03-08). Indian Statistical Institute. Retrieved from: http://ideas.repec.org/p/ind/isipdp/03-08.html

RPDRM (2012). Disaster Risk Management in food and agriculture. Rome Partnership for Disaster Risk Management. Retrieved from http://home.wfp. org/stellent/groups/public/documents/communications/wfp201794.pdf

Sarkar, A., Aronson, K. J., Patil, S., Hugar, L. B., VanLoon, G. W. (2012). Emerging health risks associated with modern agriculture practices: A comprehensive study in India, Environmental Research, 115(May 2012), 37-50.

Schaffnit-Chatterjee, C. (2010). Risk management in agriculture. Towards market solutions in the EU, Deutsche Bank Research. Retrieved from: http:// www.dbresearch.com/PROD/DBR_INTERNET_ EN-PROD/PROD0000000000262553.PDF

Shepherd, R., Barker, G., French, S., Hart, A., Maule, J., \& Cassidy, A. (2006). Managing Food Chain Risks: Integrating Technical and Stakeholder Perspectives on Uncertainty. Journal of Agricultural Economics, 57(2), 313-327. 
Sporleder, T. (1992). Managerial Economics of Vertically Coordinated Agricultural Firms. American Journal of Agricultural Economics, 74(5), 12261231.

Sutherland, L., Gabriel, D., Hathaway-Jenkins, L., Pascual, U., Schmutz, U., Rigby, ... T., Stagl, S. (2012). The 'Neighbourhood Effect': A multidisciplinary assessment of the case for farmer co-ordination in agri-environmental programmes. Land Use Policy, 29(3), 502-512.

Tummala, R., \& Schoenherr, T. (2011). Assessing and managing risks using the Supply Chain Risk Management Process. Supply Chain Management: An International Journal, 16(6), 474-483.

Trench P., Narrod, C., Roy, D., \& Tiongco, M. (2011). Responding to Health Risks along Value Chain, New Delhi: 2020 Conference Paper-5.

Ueland, Ø., Gunnlaugsdottir, H., Holm, F., Kalogeras, N., Leino, O., Luteijn, J. M., ...\& Verhagen, H. (2012). State of the art in benefit-risk analysis: Consumer perception. Food and Chemical Toxicology, 50(1), 67-76.

Vierø, M.-L. (2012). Contracting in Vague Environments. American Economic Journal: Microeconomics, 4(2), 104-130.

Weaver, R., \& Kim, T. (2000). Contracting to Manage Risk in Food Supply Chains, Paper presented at IAMA Meetings, April 2000, Chicago.

Williamson O. (1981). The Economics of Organization. The American Journal of Sociology, 87(3), 548-577.

Williamson, O. (1996). The Mechanisms of Governance. New York, NY: Oxford University Press.

Zhang, M., \& Li, P. (2012). RFID Application Strategy in Agri-Food Supply Chain Based on Safety and Benefit Analysis, Physics Procedia [Special issue: International Conference on Solid State Devices and Materials Science, April 1-2, 2012, Macao], 25, 636-642.

Zulauf, C., \& Orden, D. (2012). US Farm Policy and Risk Assistance, The Competing Senate and House Agriculture Committee Bills of July 2012 (Issue Paper No. 44). International Centre for Trade and Sustainable Development. 
